\title{
Formation of Ordered Nanostructures of Target Geometry Using Photo-Induced Volume Charge
}

\author{
M. Yu. Barabash ${ }^{1}$, I. Yu. Trosnikova ${ }^{2}$, D. S. Leonov ${ }^{1}$, R. V. Litvin ${ }^{1}$, \\ Ya. V. Bashynskyi ${ }^{1}$, and A. A. Kolesnichenko ${ }^{1}$ \\ ${ }^{1}$ Technical Centre, N.A.S. of Ukraine, \\ 13, Pokrovs'ka Str., \\ UA-04070 Kyiv, Ukraine \\ ${ }^{2}$ National Technical University of Ukraine \\ 'Igor Sikorsky Kyiv Polytechnic Institute', \\ 37, Peremogy Ave., \\ UA-03056 Kyiv, Ukraine
}

The goal of the present work is to optimize the composition of amorphous molecular semiconductor (AMS) films based on poly(N-vinylcarbazole), to upgrade the process of registration of light fields, and to reveal the role of volume charges in the formation of ordered nanostructures, using reversible templates. It is found that, when gold condenses on the AMS surface, the surface relief increases, and the distribution and symmetry of localized gold clusters are determined by the electric field pattern on the AMS surface. The role of the absorption parameter and the composite substrate is determined, basing on the study of the absorption parameters of the composite with photo-induced charge. The optimal conditions of the composite application for the study of the spectral characteristics of the investigated structures are determined.

Метою даної роботи є оптимізація складу аморфних молекулярних напівпровідникових (AMH) плівок на основі полі(N-вінілкарбазолу), вдосконалення процесу реєстрації світлових полів і виявлення ролі об’ємних зарядів у формуванні впорядкованих наноструктур із використанням оборотніх шаблонів. Встановлено, що, коли золото конденсується на АМН-поверхні, рельєф поверхні збільшується, а розподіл і симетрія локалізованих скупчень золота визначаються структурою електричного поля на АMН-поверхні. Визначено роль параметра поглинання та композитної підкладинки, грунтуючись на вивченні параметрів поглинання композиту зі світлоіндукованим зарядом. Визначено оптимальні умови застосування композиту для вивчення спектральних характеристик досліджуваних структур. 
Key words: template, films, photo-induced volume charge, metal-dielectric composites, nanocomposites, nanoclusters, near-field interaction.

Ключові слова: шаблон, плівки, світлоіндукований об’ємний заряд, металодіелектричні композити, нанокомпозити, нанокластери, близькопольова взаємодія.

(Received 10 February, 2021; in revised form, 3 March, 2021)

\section{INTRODUCTION}

Recent investigations in the field of optical technologies are aimed at the development of devices with sub-wavelength dimensions, in which photon are operated by means of nanoscale optical phenomena. Therefore, there is a fundamental discrepancy between the scale of nanodevices and the wavelength of light (order of a micrometer). In many materials, the intensity of the interaction of light with matter decreases as $(a / \lambda)^{2}$, where $a$ is the scale of the material structure, and $\lambda$ is the wavelength of light. However, there are surface plasmons in metals; so, metals can concentrate electromagnetic (EM) fields in regions with smaller dimensions as compared to the wavelength, while the local field is simultaneously increasing by several orders of magnitude. Thus, it becomes urgent to develop a technology for the fabrication of metal-dielectric composites with various topologies.

According to the modern electrodynamics [1] of these composites, the signal amplification factor is described by the expression $\left|E(\mathbf{r}) / E_{0}\right|$, where $E(\mathbf{r})$ is the local electric field, and $E_{0}$ is the amplitude of the incident field. The enhancement of local fields in nanostructured materials strongly depends on the ratio of the diameter of the particles, $a$, and the distance between these nanoparticles, $\delta$. The diameter of the particles should be much smaller than the wavelength of the incident light $(\alpha<\lambda)$, in order to be fulfilled the quasi-static approximation $(\alpha+\delta<\lambda)$ between the size of nanoparticles and the diffraction pattern period.

In this case, the ratio $\left|E(\mathbf{r}) / E_{0}\right|$ can be calculated as a continuous function of the lattice packing density, which is described by single geometric parameter $\gamma=a / \delta$, where $\delta$ is the smallest distance between the particles. The increase in the intensities of the local and average EM fields largely depends on both the wavelength of the incident radiation and the diameter/distance ratio, $\gamma$. Metaldielectric composites with large geometric parameter $\gamma$ can provide greater field amplification in a wider range of exciting radiation wavelengths. This has important practical uses. High values of optical amplification are explained by the presence of resonant modes 
in periodically ordered structures, and by the existence of giant fluctuations of local fields between particles, which determine the ability of the composite to accumulate and reveal EM energy. These fluctuations are provided by the large effective absorption, which should be inherent to the composite. However, under strong localization of field, the probability of detecting exogenous molecules decreases as compared to the case with less localized EM field. Therefore, the diameter/distance ratio should be optimized close to the threshold value $\gamma$ within the largest possible volume of the composite. The threshold value $\gamma$ can be determined, using the percolation model for fluctuations of local fields in the composite. The behaviour of metal-dielectric composites near the percolation threshold has been the subject of numerous studies [1-5].

According to this model [1], the composite undergoes a metalinsulator transition upon reaching the percolation threshold $p=p_{c}$. In this case, the characteristics of the composite (conductivity, dielectric susceptibility, the probability of formation of an infinite cluster of conducting material) are functions of the conductivity of the metal layer $p$ and have a singular behaviour near the percolation threshold. The same model predicts that metal-dielectric composites with zero losses, which have higher absorption at the frequencies below the plasmon frequency, have higher values of local EM fields. Thus, one can assume that giant field fluctuations will be realized near the percolation threshold at concentrations $p \cong p_{c}$, when absorption can reach $50 \%$, so that EM energy can be accumulated in the metal-dielectric composite; systems with high absorption will have intense local fields. This assumption is of great importance, as it allows introducing a criterion for evaluating local fields in the developed metal-dielectric structures.

\section{METHOD FOR FABRICATION OF ORDERED STRUCTURES}

There is a problem of fabrication of ordered structures at the nanoscale. There are two known methods of synthesizing ordered structures: top-down and bottom-up ones.

In the present work, a method based on a light-controlled template was used for the fabrication of ordered structures. The template is a system functionally organized in space that allows structuring nanoscale objects because of the near-field interaction of these objects with the template structure. The use of photosensitive AMS films with thermoelectret properties made it possible to fabricate templates with volume charge and electric field $E \sim 10^{7} \mathrm{~V} / \mathrm{mm}$ structured by the light field. The fabrication of ordered nanostructures involved three stages. At the first stage of the process, a composite (PVC) was obtained in a thin film of photosensitive AMS 
deposited by physical vapour deposition technique in a 'VUP-5M' unit on a glass substrate $(d=3 \mathrm{~mm})$ coated with an ITO layer with copper electrical contacts. The ITO (indium tin oxide- $\operatorname{In}_{2} \mathrm{O}_{3}\left(\mathrm{SnO}_{2}\right)$ ) layer consisted of 90 wt. $\% \operatorname{In}_{2} \mathrm{O}_{3}$ and 10 wt. $\% \mathrm{SnO}_{2}$ compound Solid solution of this compound is optically transparent and has high electrical conductivity $(20 \mathrm{Ohm} /$ square $)$ that allows it to pass electric currents up to $10 \mathrm{~A} / \mathrm{cm}$. At the second stage, the top-down method was used in the electrographic process of holographic lithography on AMS films. The polymer template was fabricated in three stages (Fig. 1).

$1^{\text {st }}$ stage: uniform deposition of positive charge in a corona discharge on the surface of the polymer semiconductor (AMS) film.

$2^{\text {nd }}$ stage: exposure to the light field; as a result, the modulation of the surface density of electrostatic charge, the formation of an electrostatic image due to photo-induced conductivity of the AMS, and trapping of current carriers by deep traps occurred.

$3^{\text {rd }}$ stage: controlled heating of AMS; as a result, the surface relief was formed on the AMS, and thermally stimulated electric charge appeared in the AMS volume. After heating, the AMS was rapidly cooled to fix the surface relief.

For the exposure of the template, three laser beams directed to the base along the lateral surface of a right cone with an apex angle

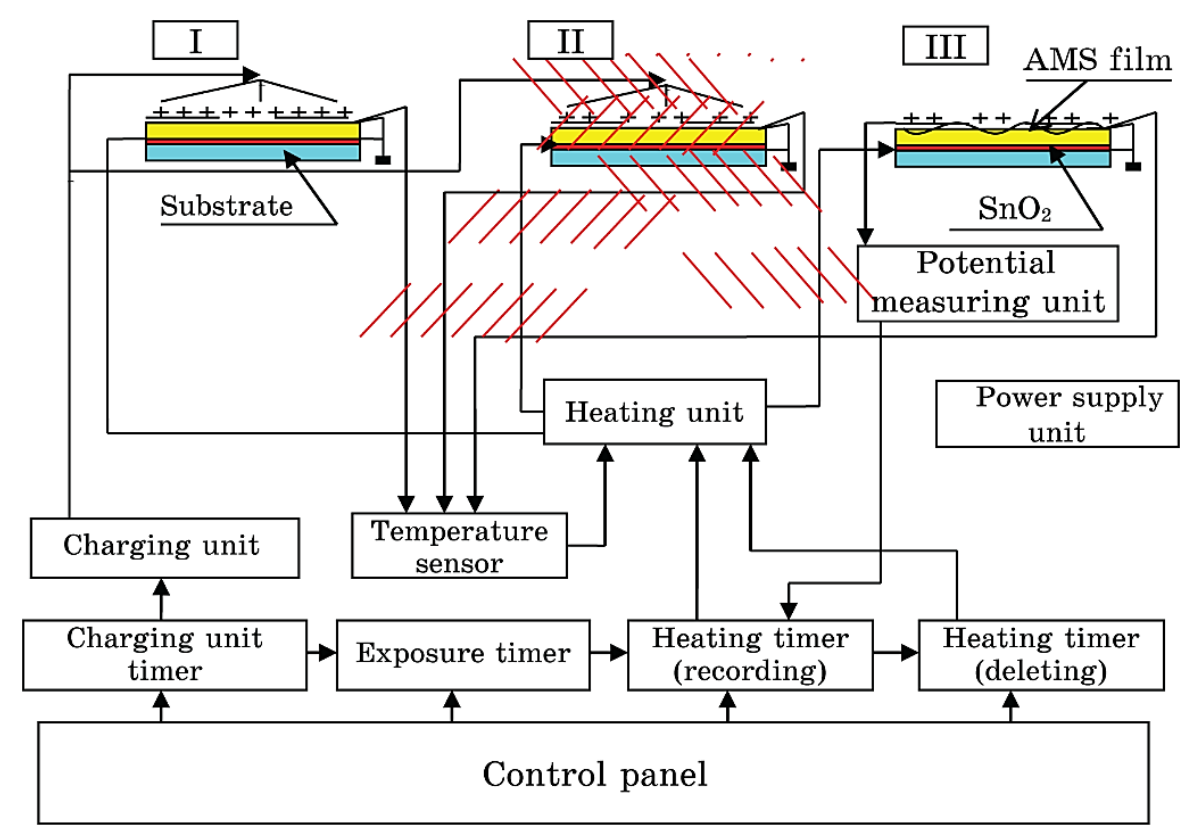

Fig. 1. Block diagram of template fabrication process. 
of $25^{\circ}$ were used. Under the exposure to the light in the electric field of flat capacitor formed by the conductive composite layer and the surface charge of AMS, the photo-generation of current carriers occurs and photoconductivity appears in the AMS [6-9]. The photocurrents result to a decrease in the potential of film surface. Under the exposure, the surface charge is distributed on the AMS surface; the charge distribution is determined by the light field. The spatially modulated field of surface charges can deform the film surface when it softens. The time of formation of the AMS surface relief was $0.05 \mathrm{~s}$. The reconstruction of the process characteristics was provided by automatic hologram registration, using the control module [10].

At the third stage, gold layers of various thicknesses $(50 \mathrm{~nm} \times 0.5$ $\mu \mathrm{m})$ were applied on the AMS surface by thermal evaporation in vacuum.

The polymer template was fabricated with the following parameters:

spectral sensitivity range: $0.4-0.9 \mu \mathrm{m}$;

diffraction efficiency limit (DE) of $20 \%$;

holographic sensitivity: $\lambda=0.63$ and $\mathrm{DE}=1 \%, 500 \mathrm{~m}^{2} / \mathrm{J}$;

spatial frequency bandwidth: $300-1000$ lines $/ \mathrm{mm}$;

hologram development time (10-150) $10^{-3} \mathrm{~s}$ for the composite on

a glass substrate;

size of AMS working surface: $3 \times 4 \mathrm{~cm}$;

overall dimensions of the device: $200 \times 500 \times 100 \mathrm{~mm}$.

\section{DISCUSSION}

When the AMS is heated in the intense field of modulated positive surface charge $\left(E=10^{8} \mathrm{~V} / \mathrm{m}, \delta E=10 \%\right)$, thermally stimulated trapping of charge carriers occurs on deep traps, and volume charge is formed in the AMS. The probability of charge trapping is determined by the density and energy characteristics of deep traps in the AMS. Therefore, when the film is irradiated, it is possible not only to form the surface relief on the AMS (relief template), but also to obtain trapped charge (electret template), according to the scheme shown in Fig. 2. The density of the localized volume electric charge turns out to be modulated by the intensity of the light field in the exposing hologram and, therefore, has the same topology.

As seen from Fig. 2, volume charge of negative polarity is formed in the AMS at the initial stage of the AMS relief development. The methods of optical holography, optical and electron microscopy, and AFM showed the adequacy of the topology of light field and the distribution of volume charge in the AMS to the topology of the fabricated and replicated structures. 


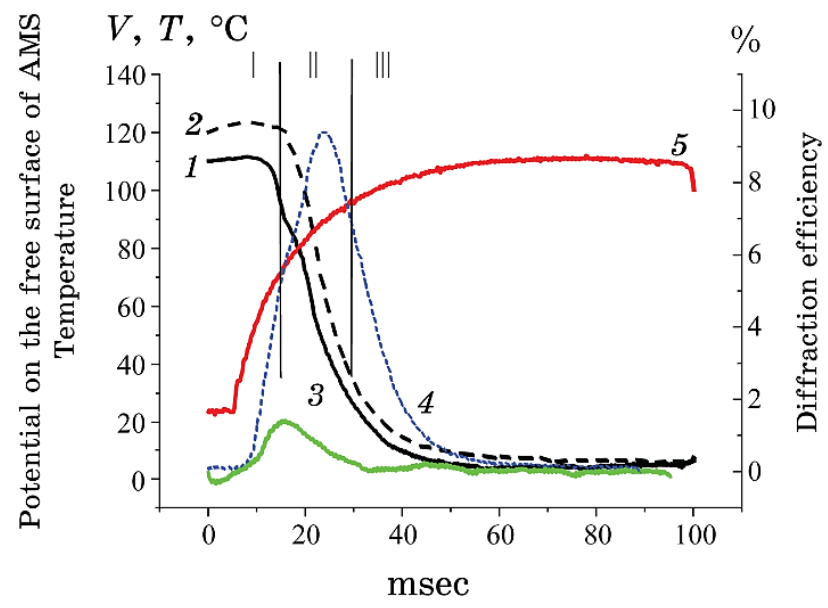

Fig. 2. Relaxation kinetics of potential on the free surface of AMS film: 1 -relaxation of electric potential on the AMS free surface without preliminarily formed volume charge (thermally stimulated charge); 2-relaxation of electric potential on the AMS free surface with preliminarily formed volume charge; 3 -relaxation of a thermally stimulated charge in the AMS volume; 4-formation of AMS surface relief; 5-AMS temperature changes.

The templates of different geometries were obtained by means of the process described above (Fig. 3).

Typical images of the template surface obtained at an optical microscope are shown in Fig. 4. The modulated surface relief of film formed the two-dimensional spatially periodic structure; Fig. 4, a represents the topology of the light field of exposing hologram.

The study of gold film deposition on the AMS surface showed that, even in the case of AMS with smooth surface, this process occurred in accordance with the pattern of the light field applied. For the AMS with relief amplitude of about $50 \mathrm{~nm}$, it was possible to increase it up to $200 \mathrm{~nm}$ by gold deposition (Fig. 5).

During the deposition of gold on the template surface in vacuum, a system of spatially ordered gold clusters formed on the surface (Fig. 4, b). It should be noted that gold condensed in certain clearly localized areas; it was not evenly distributed on the surface. One would expect that, during deposition onto a surface with developed relief, gold adatoms will gather mainly at the bottom of the dimples, but this did not happen. The location and symmetry of the deposited gold clusters are determined by the light field topology. The surface of the polymer template under discussion had a periodic relief with peaks' height of about $350 \mathrm{~nm}$ (Fig. 5), whereas, for the template coated by gold, the height was of $500 \mathrm{~nm}$. Depending on 

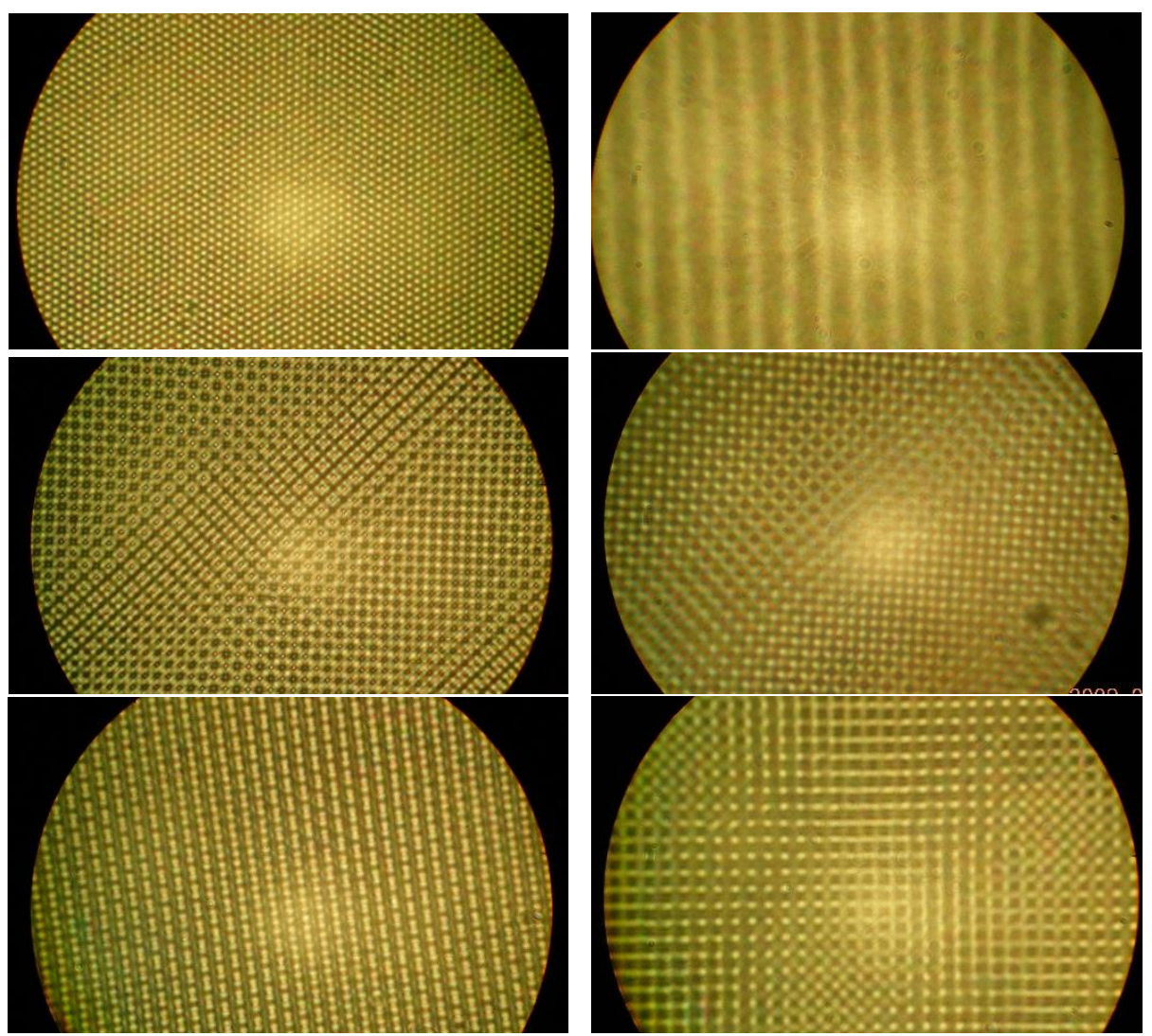

Fig. 3. The template surfaces. Optical microscope 'Biolam', structure period $d=2 \mu \mathrm{m}$.

the intensity of the beam and deposition time, the size of gold islands can be varied from just adsorbed layer to several micrometers.

A comparison of the topology of the exposing light field, which is visualized as a profile of the surface relief (Fig. 5, a), and the topology of the surface after gold deposition (Fig. 5, $b$ ) allows to conclude that the gold islands formed exclusively in the areas of minimum light intensity, which corresponded to the maximum values of the local field $\mathbf{E}$ of the trapped charge in the surface layer. Electric field with a significant intensity gradient was localized in the areas where electric charge was trapped in the photoconductive film during exposure to the light field. Gold clusters were not observed in the dimples where the intensity of the exposing light field had a maximum and the trapped charge did not form (Fig. 5, b).

The electric field in these zones was estimated by the method in Ref. [11] by means of comparing the reliefs formed in the field of 

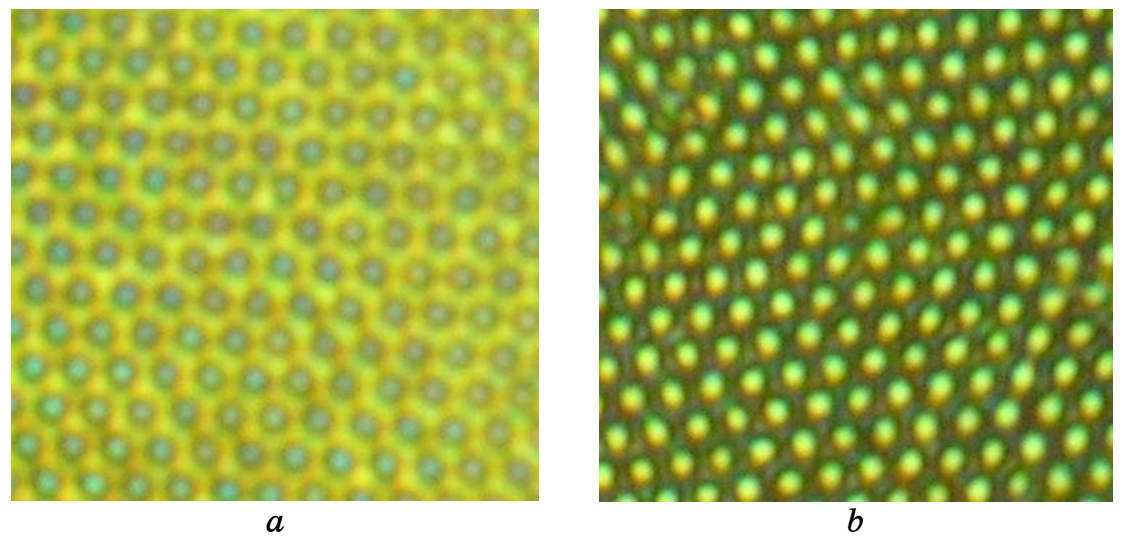

Fig. 4. The template surface (optical microscope 'Biolam', magnification $\times 800$ ): $a$-AMS surface before gold deposition; $b$-AMS surface after gold deposition. Structure period is of about $2 \mu \mathrm{m}$.
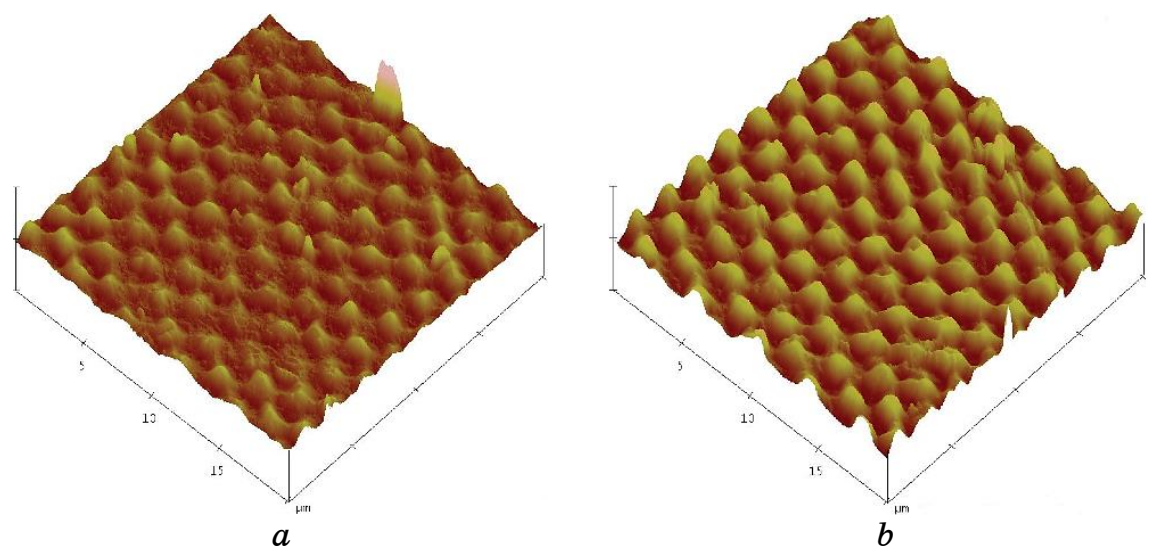

Fig. 5. AFM images of the template surface: $a$-AMS surface relief before gold deposition; $b$-AMS surface relief after gold deposition. The structure period is of $\cong 2 \mu \mathrm{m}$, gold film thickness is of $50 \mathrm{~nm}$.

surface and localized volume charges. The average value of the potential on the film surface in the electret state was of $80 \mathrm{~V}$, and the modulation amplitude of the surface, assuming a sinusoidal distribution, reached $12 \mathrm{~V}$ at a film thickness of $820 \mathrm{~nm}$ and a period of the formed structure of $2.1 \mu \mathrm{m}$. The dielectric constant of the nanocomposite was estimated as the square of the refractive index (its typical value for carbazolyl-containing polymers is of 1.4). Therefore, the electric field localized in the thickness of film can be estimated as of $100 \mathrm{MV} / \mathrm{m}$ with a modulation of $10 \%$. 


\section{CONCLUSIONS}

The composition of AMS films and the process of recording light fields are optimized. The role of volume charges in the formation of ordered nanostructures using reversible templates is determined. It is found out that the surface relief increases after deposition of gold on the AMS surface; the distribution and symmetry of localized gold particles are determined by the pattern of electric field on the AMS surface. The role of the absorption parameter and the effect of the composite substrate were clarified, basing on the study of absorption modes of the composite with photo-induced charge. The optimal conditions for the formation of local fields in the composite were determined by studying the spectral parameters of its absorption.

It is shown that the electrophysical properties of AMS largely control the parameters of the template, affect the deposition of gold films, the polariton-plasmon characteristics of the composite, and the appearance and existence of large fluctuations of EM field of the composite. A laboratory prototype of an automated device for the fabrication of reversible templates with photo-induced charge and a technology for the forming ordered structures are developed and tested.

\section{REFERENCES}

1. A. K. Sarychev and V. M. Shalaev, Ehlektrodinamika Metamaterialov (Nauchnyi Mir: 2011) (in Russian).

2. A. K. Sarychev and V. M. Shalaev, Phys. Rep., 335: 275 (2000).

3. S. Kirkpatrik, Rev. Mod. Phys., 45: 574 (1973).

4. J. P. Clerc, G. Giraud, and J. M. Luck, Adv. Phys., 39: 191 (1990).

5. D. J. Bergman and D. Stroud, Solid State Phys., 46: 147 (1992).

6. M. Yu. Barabash, Nanosistemi, Nanomateriali, Nanotehnologii, 7, No. 2: 403 (2009) (in Ukrainian).

7. M. Yu. Barabash, V. E. Martynchuk, and R. V. Litvin, J. of Nano- and Electronic Physics, 9, No. 2: 02020(6cc) (2017) (in Russian); doi:10.21272/jnep.9(2).02020

8. M. Yu. Barabash, R. V. Litvin, D. S. Leonov, A. A. Kolesnichenko, V. Eh. Martynchuk, and L. V. Ryabov, Nanosistemi, Nanomateriali, Nanotehnologii, 16, No. 1: 153 (2018) (in Russian); https://doi.org/10.15407/nnn.16.01.153

9. S. G. Grenishin, Ehlektrofotograficheskiy Protsess (Moscow: Nauka: 1970) (in Russian).

10. M. Yu. Barabash, D. O. Hrynko, and S. O. Sperkach, Formuvannya Nanostruktur na Templatakh Vyprominyuvannyam iz Vydymoho Diapazonu (Kyiv: Instytut metalofizyky im. G. V. Kurdyumova NAN Ukrainy: 2015) (in Ukrainian).

11. M. A. Zabolotnyi, Eh. L. Martynchuk, D. O. Hrynko, M. Yu. Barabash, 
M. P. Kulish, O. P. Dmytrenko et al., Sposib Stvorennya Dvovymirnoyi Nadgratky $z$ Uporyadkovanykh Nanoklasteriv na Poverkhni Fotoprovidnogo Termoplastychnogo Sharu (Patent na Korysnu Model No. 58732. Ukrayina MPK G03H 1/100. No. u201011133; Zayavl. 16.09.2010. Opubl. 26.04.2011. Byul. No. 8) (in Ukrainian). 